\title{
Markedly Accelerated Catabolism of Apolipoprotein A-II (ApoA-II) and High Density Lipoproteins Containing ApoA-II in Classic Lecithin: Cholesterol Acyltransferase Deficiency and Fish-Eye Disease
}

\author{
Daniel J. Rader, Katsunori Ikewaki, Nicolas Duverger, Hartmut Schmidt, Hadyn Pritchard, ${ }^{*}$ Jiri Frohlich, ${ }^{*}$ Michel Clerc, ${ }^{*}$ \\ Marie-France Dumon, ${ }^{*}$ Thomas Fairwell, Loren Zech, Silvia Santamarina-Fojo, and H. Bryan Brewer, Jr. \\ Molecular Disease Branch, National Heart, Lung, and Blood Institute, National Institutes of Health, \\ Bethesda, Maryland 20892; *Lipoprotein Research Group, University of British Columbia, Vancouver, \\ British Columbia V5Z 4H4, Canada; and ${ }^{\ddagger}$ Laboratoire Central de Biochimie, Hôpital Saint-André, 33075 Bordeaux, France
}

\begin{abstract}
Classic (complete) lecithin:cholesterol acyltransferase (LCAT) deficiency and Fish-eye disease (partial LCAT deficiency) are genetic syndromes associated with markedly decreased plasma levels of high density lipoprotein (HDL) cholesterol but not with an increased risk of atherosclerotic cardiovascular disease. We investigated the metabolism of the HDL apolipoproteins (apo) apoA-I and apoA-II in a total of five patients with LCAT deficiency, one with classic LCAT deficiency and four with Fish-eye disease. Plasma levels of apoA-II were decreased to a proportionately greater extent ( $23 \%$ of normal) than apoAI ( $30 \%$ of normal). In addition, plasma concentrations of HDL particles containing both apoA-I and apoA-II (LpA-I:A-II) were much lower ( $18 \%$ of normal) than those of particles containing only apoA-I (LpA-I) (51\% of normal). The metabolic basis for the low levels of apoA-II and LpA-I:A-II was investigated in all five patients using both exogenous radiotracer and endogenous stable isotope labeling techniques. The mean plasma residence time of apoA-I was decreased at $2.08 \pm 0.27 \mathrm{~d}$ (controls $4.74 \pm 0.65$ days); however, the residence time of apoA-II was even shorter at $1.66 \pm 0.24 \mathrm{~d}$ (controls $5.25 \pm 0.61$ d). In addition, the catabolism of apoA-I in LpA-I:A-II was substantially faster than that of apoA-I in LpA-I. In summary, genetic syndromes of either complete or partial LCAT deficiency result in low levels of HDL through preferential hypercatabolism of apoA-II and HDL particles containing apoA-II. Because LpA-I has been proposed to be more protective than LpA-I:A-II against atherosclerosis, this selective effect on the metabolism of LpA-I:A-II may provide a potential explanation why patients with classic LCAT deficiency and Fish-eye disease are not at increased risk for premature atherosclerosis despite markedly decreased levels of HDL cholesterol and apoA-I. (J. Clin. Invest. 1994. 93:321-330.) Key words: apolipoprotein A-I • atherosclerosis • cholesterol • kinetics • stable isotopes
\end{abstract}

\section{Introduction}

Epidemiologic studies have consistently demonstrated that plasma concentrations of HDL cholesterol are inversely corre-

Address correspondence to Dr. Daniel Rader, Building 10, Room 7N117, National Institutes of Health, 9000 Rockville Pike, Bethesda, MD 20892. 1993.

Received for publication 15 April 1993 and in revised form 5 August

The Journal of Clinical Investigation, Inc.

Volume 93, January 1994, 321-330 lated with the incidence of coronary heart disease (CHD) ${ }^{1}(1)$. However, the physiologic mechanism(s) by which HDL may protect against premature $\mathrm{CHD}$ are not well understood. HDL are heterogeneous in size, hydrated density, and apolipoprotein composition. The major apolipoproteins in HDL are apoA-I and apoA-II. Plasma concentrations of apoA-I have been shown to have a strong inverse correlation with risk of CHD, whereas a correlation of CHD risk with apoA-II levels has not been consistently demonstrated (2). The plasma catabolism of apoA-II is slower than that of apoA-I in normal human subjects (3-6), suggesting that these apolipoproteins have divergent in vivo metabolism.

There are several subclasses of apoA-I-containing particles within HDL, including particles that contain both apoA-I and apoA-II (LpA-I:A-II) and those that contain apoA-I but not apoA-II (LpA-I) $(7,8)$. In normal individuals, approximately one third of plasma apoA-I is in LpA-I and two thirds in LpAI:A-II (8-10). LpA-I and LpA-I:A-II have different in vivo metabolism in normal subjects, with more rapid catabolism of apoA-I on LpA-I (11). Several lines of evidence suggest that LpA-I, but not LpA-I:A-II, may be a specific "anti-atherogenic" particle within HDL. These include epidemiologic (1214), cell culture (15), and whole animal (16-18) studies.

One mechanism by which HDL are believed to protect against CHD is through a process termed "reverse cholesterol transport." In this process, HDL facilitates the removal of excess unesterified cholesterol from peripheral cells, after which the cholesterol is esterified by the plasma enzyme lecithin:cholesterol acyltransferase (LCAT) (19-22). Hence, LCAT is believed to play an important role in the process of reverse cholesterol transport: by esterifying cholesterol in HDL it creates a gradient of unesterified cholesterol from cells to HDL particles and permits the specific transport of cholesteryl ester within the hydrophobic core of lipoprotein particles.

Two general types of genetic LCAT deficiency have been described in humans. The first, complete (or classic) LCAT deficiency, is characterized clinically by corneal opacities, anemia, and usually progressive proteinuria and renal insufficiency (23). Very low plasma levels of HDL cholesterol, a high fraction of plasma cholesterol in the unesterified form, and virtually complete absence of cholesterol esterification in the plasma are the biochemical hallmarks of this disorder. Several different mutations in the LCAT gene have been described in

1. Abbreviations used in this paper: $\mathrm{CER}$, cholesterol esterification rate; CHD, coronary heart disease; FCR, fractional catabolic rate; FSR, fractional synthetic rate; LpA-I:A-II and LpA-I, lipoprotein particles that contain both apoA-I and apoA-II and those that contain apoA-I but not apoA-II, respectively. 
patients with classic LCAT deficiency (24-29). A second type of LCAT deficiency is a partial deficiency that has been designated Fish-eye disease (23). The clinical features similar to classic LCAT deficiency include corneal opacities and very low levels of HDL cholesterol. However, Fish-eye disease patients have no anemia or renal disease, the fraction of plasma cholesteryl ester is normal, and there is clearly detectable cholesterol esterification activity in the plasma. The initial patients reported with Fish-eye disease had evidence of cholesterol esterification in apoB-containing lipoproteins but not in HDL (30, 31 ). At least four different molecular defects in the LCAT gene have been described in patients with Fish-eye disease (32-35).

In addition to the low plasma levels of HDL cholesterol, both types of LCAT deficiency are associated with very low plasma levels of both apoA-I and apoA-II. Notably, despite the markedly low levels of HDL cholesterol, apoA-I, and apoA-II, there is no apparent increased risk of premature atherosclerotic cardiovascular disease in either complete or partial LCAT deficiency (23). In order to gain further insight into the metabolic basis of the hypoalphalipoproteinemia and the absence of premature cardiovascular disease in these disorders, we investigated the in vivo metabolism of apoA-I, apoA-II, LpA-I, and LpA-I:A-II in five probands with complete or partial LCAT deficiency using both exogenous radiotracer and endogenous stable isotope labeling techniques.

\section{Methods}

Study subjects. One patient with complete (classic) LCAT deficiency and four patients with partial LCAT deficiency (Fish-eye disease) were investigated. Their clinical characteristics are summarized in Table I. The complete LCAT-deficient patient (no. 1) presented at the age of 17 yr with proteinuria and anemia. A renal biopsy was consistent with the diagnosis of classic LCAT deficiency. His older brother, who also has LCAT deficiency, developed renal failure at the age of 28 yr requiring dialysis. Their renal histopathology has been previously reported (36). At the time of his kinetic study, the patient had moderate proteinuria and mild renal insufficiency but no evidence of nephrotic syndrome (Table I). His molecular defect has not been established.

One partial LCAT-deficient patient (no. 2) was diagnosed at the age of $17 \mathrm{yr}$ when found to have a very low plasma HDL cholesterol and has been previously reported (37). He was recently determined to be a compound heterozygote for two missense mutations in the LCAT gene: Met $_{252}$ to Lys and Asn ${ }_{391}$ to Ser (H. Pritchard, unpublished data). Two of the probands with partial LCAT deficiency (nos. 3 and 4) are siblings who were diagnosed at the ages of 53 and 49 yr after a long history of corneal opacities, requiring corneal transplant in one (38). Both were recently found to be homozygotes for a deletion of $\mathrm{Leu}_{300}$ in the LCAT gene (35). The final proband with partial LCAT deficiency (no. 5) was diagnosed at the age of $63 \mathrm{yr}$ because of severe corneal opacities. The biochemical and molecular analysis of this patient has been reported (34); he is a compound heterozygote for two missense mutations in the LCAT gene, $\mathrm{Thr}_{123}$ to Ile and $\mathrm{Thr}_{347}$ to Met.

None of the patients with partial LCAT deficiency had evidence of anemia or renal disease (Table I). Clinical evidence of coronary heart disease was absent in all five of the patients. In addition, three of the patients (nos. 1, 3, and 4) had no evidence of coronary calcification by ultrafast computed tomography scanning (39), a sensitive noninvasive method for detecting coronary atherosclerosis.

Both exogenous radiotracer and endogenous stable isotope labeling methods were used to investigate apoA-I and apoA-II kinetics. Three patients (nos. 2-4) had simultaneous exogenous radiotracer and endogenous stable isotope kinetic studies performed, whereas the complete LCAT-deficient patient (no. 1) had a radiotracer study and one partial LCAT-deficient patient (no. 5) had a stable isotope study performed.

Control subjects were healthy and had normal fasting plasma lipid and apolipoprotein levels. During the studies, all study subjects were placed on a controlled metabolic diet containing $47 \%$ carbohydrate, $37 \%$ fat, $16 \%$ protein, and $200 \mathrm{mg}$ cholesterol per $1,000 \mathrm{kcal}$. The protocols were approved by the Internal Review Board of the National Heart, Lung, and Blood Institute and all study subjects gave informed written consent.

Exogenous radiotracer studies. ApoA-I and apoA-II were isolated from the HDL of a healthy subject with normal lipid values by gel permeation and ion exchange chromatography as previously described $(40,41)$. Apolipoproteins were iodinated by a modification of the iodine monochloride method as previously reported (11). Approximately 0.5 mol iodine was incorporated per mol protein. ${ }^{125} \mathrm{I}$-apoA-I and ${ }^{131} \mathrm{I}$-apoA-II were reassociated with autologous plasma and dialyzed extensively to remove free iodine. Human serum albumin was added to a final concentration of $5 \%(\mathrm{wt} / \mathrm{vol})$. Samples were sterile filtered and tested for pyrogens and sterility.

$1 \mathrm{~d}$ before the start of the study, the subjects were given potassium iodide at a dose of $900 \mathrm{mg} / \mathrm{d}$ in divided doses and this was continued for the duration of the study. After a 12-h fast, subjects were injected intravenously with the iodinated apolipoproteins. Blood was drawn into tubes containing EDTA (0.1\%) 10 min after injection and then at selected time points through $14 \mathrm{~d}$. Urine was collected continuously through $14 \mathrm{~d}$. Radioactivity in plasma and urine was quantitated in a Cobra gamma counter (Packard Instrument Co., Downers Grove, IL). Residence times (RT) were obtained from the area under the plasma radioactivity curves using a multiexponential computer curve-fitting technique (42). Fractional catabolic rates (FCR) are the reciprocal of residence times. The fractional standard deviations of the kinetic parameters were always $<2 \%$. Apolipoprotein production rates (PR) were determined using the formula: $P R=$ (plasma apolipoprotein concentration $) \times($ volume of distribution $) /(R T) \times($ body weight $)$. The volume of distribution was determined by isotope dilution from the 10-min plasma sample.

Table I. Clinical Characteristics of LCAT-deficient Study Subjects

\begin{tabular}{|c|c|c|c|c|c|c|}
\hline Subjects & Sex & Age & BMI & Hemoglobin & Creatinine & Urine protein \\
\hline & & $y r$ & $\mathrm{~kg} / \mathrm{m}^{2}$ & $g / d l$ & $m g / d l$ & $g / d$ \\
\hline \multicolumn{7}{|c|}{ Complete LCAT deficiency } \\
\hline 1 & $\mathbf{M}$ & 25 & 25.6 & 12.0 & 1.9 & 5.7 \\
\hline \multicolumn{7}{|c|}{ Partial LCAT deficiency } \\
\hline 2 & $\mathbf{M}$ & 21 & 21.7 & 13.6 & 1.2 & $<0.5$ \\
\hline 3 & $\mathbf{M}$ & 55 & 24.9 & 14.6 & 1.2 & $<0.5$ \\
\hline 4 & $\mathbf{F}$ & 53 & 23.0 & 13.1 & 0.8 & $<0.5$ \\
\hline 5 & $\mathbf{M}$ & 67 & 21.1 & 14.5 & 1.1 & $<0.5$ \\
\hline
\end{tabular}

Abbreviation: BMI, body mass index. 
Endogenous stable isotope studies. Endogenous labeling of apoA-I and apoA-II with a stable isotopically labeled amino acid was performed in all four partial LCAT-deficient patients. The labeled amino acid used was a three-times deuterium-labeled L-leucine, with the three deuteriums positioned on the methyl group (MSD Isotopes, St. Louis, $\mathrm{MO}$ ). The $\mathrm{D}_{3}$-leucine was dissolved in physiological salt solution, sterile filtered, and tested for pyrogenicity and sterility before the study. The $\mathrm{D}_{3}$-leucine was administered as a priming bolus of $1.2 \mathrm{mg} / \mathrm{kg}$, immediately followed by a constant infusion of $24 \mu \mathrm{g} / \mathrm{kg}$-min over a period of 12-16 h. Blood samples were drawn $10 \mathrm{~min}$ before the priming bolus and then at selected times during the course of the constant infusion. During the infusion meals were provided in small equal portions every $2 \mathrm{~h}$.

Free plasma amino acids were isolated from $0.5 \mathrm{ml}$ of plasma by cation exchange column chromatography as previously described (43). Apolipoproteins were analyzed for enrichment with the $D_{3}$-leucine as previously described (44). Briefly, lipoprotein subfractions were isolated by sequential ultracentrifugation of $5 \mathrm{ml}$ of plasma from selected time points. In addition, total plasma lipoproteins were isolated after adjusting the plasma to a density of $1.25 \mathrm{~g} / \mathrm{ml}$ and ultracentrifuging for $8 \mathrm{~h}$ in a tabletop model TL-100 ultracentrifuge (Beckman Instruments, Inc., Fullerton, CA). ApoB-100, the major structural protein of VLDL, was isolated from delipidated VLDL by preparative discontinuous gradient SDS-PAGE (5/15\% acrylamide). ApoA-I and apoA-II were isolated from the total plasma lipoprotein fraction by $5 / 15 \%$ SDS-PAGE (apoA-I) and preparative isoelectric focusing (apoA-II). Apolipoproteins were hydrolyzed and amino acids were recovered by cation exchange chromatography and derivatized to the $N$-heptafluorobutyryl isobutyl esters.

The isotope ratios of $\mathrm{D}_{3}$-leucine were quantitated by gas chromatograph-mass spectrometry on a Finnigan MAT model 4500 (Finnigan MAT, San Jose, CA) in the chemical ionization mode. The selected positively charged ions of $384 \mathrm{~m} / z$ for leucine and $387 \mathrm{~m} / z$ for $\mathrm{D}_{3}$-leucine were monitored. At least three measurements were made of each apolipoprotein at each time point. The isotope ratio (IR) was defined as the ratio of $\mathrm{D}_{3}$-leucine to unlabeled leucine. The enrichment (e) was determined by the formula $e=\left(I R_{t}-I R_{0}\right) \times 100$, where $I R_{t}$ is the isotope ratio at time $t$ and $I R_{0}$ is the isotope ratio at time $0(45)$. The enrichment was then converted to the tracer/tracee ratio (45) by using the formula tracer/tracee ratio $=e(t) /\left[e_{I}-e(t)\right]$, where $e(t)$ is the enrichment of each sample at time $t$, and $e_{\mathrm{I}}$ is the enrichment of the infusate ( 0.99 for the $\mathrm{D}_{3}$-leucine used in this study).

The tracer/tracee ratio data of VLDL apoB-100, apoA-I, and apoA-II were simultaneously fitted to monoexponential functions using the SAAM 30 program (42). The function was defined as tracer/ tracee ratio $=A_{p}\left(1-e^{-[k(t-d)]}\right)$, where $A_{\mathrm{p}}$ is the precursor pool tracer $/$ tracee ratio for the apolipoprotein, $k$ is the fractional synthetic rate (FSR), and $d$ is the delay. The FSR is equal to the FCR at steady state. Tracer/tracee ratios from VLDL apoB-100, apoA-I, and apoA-II were simultaneously analyzed using the VLDL apoB-100 plateau tracer/tracee ratio as the estimate of the precursor pool IE for VLDL apoB-100 and plasma apoA-I and apoA-II $(44,46,47)$. Theoretical concerns have been raised about the use of VLDL apoB-100 (a primarily liverderived protein) to estimate precursor enrichment for apoA-I (a protein derived from both liver and intestine). However, we have established that apoA-I FSRs determined by using the VLDL apoB-100 plateau tracer/tracee ratio as an estimate of the precursor pool tracer/ tracee ratio for apoA-I synthesis were in excellent quantitative agreement with apoA-I FCRs obtained simultaneously using exogenously radiolabeled apoA-I (48). Furthermore, in one patient with very rapid catabolism of apoA-I, the apoA-I tracer/tracee ratio reached a plateau that was $91 \%$ that of VLDL apoB-100 (49). Hence, the use of the VLDL apoB-100 plateau represents a reasonable estimate of apoA-I precursor tracer/tracee ratio.

Isolation of LpA-I and LpA-I:A-II by immunoaffinity chromatography. LpA-I and LpA-I:A-II were isolated as previously described (11). $60 \mu$ l of plasma from selected time points after injection was applied to small analytical anti-apoA-II immunoaffinity columns equilibrated with PBS $/ 0.01 \%$ EDTA. Nonspecific binding was removed by washing with $1 \mathrm{M} \mathrm{NaCl}$, and the apoA-II-containing particles (LpA-I:A-II) bound to the column were eluted with $3 \mathrm{M} \mathrm{NaSCN}$. The radioactivity in both the nonretained and retained fractions was quantitated. No radiolabeled apoA-II was found in the nonretained fraction from the anti-apoA-II column. The quantity of radiolabeled apoA-I in the nonretained (LpA-I) and retained (LpA-I:A-II) was determined as a fraction of the total recovery from the column.

Ultracentrifugation procedures. VLDL, LDL, $\mathrm{HDL}_{2}, \mathrm{HDL}_{3}$, and the $d>1.21 \mathrm{~g} / \mathrm{ml}$ fractions were isolated from $5 \mathrm{ml}$ of plasma by sequential ultracentrifugation (50) and tube slicing. Radioactivity in the supranatant and infranatant fractions was determined after each centrifugation, and the ratio of radioactivity in the top/(top + bottom) was used to determine the total radioactivity in each density fraction at each time point.

Analytical methods. LCAT activity and the cholesterol esterification rate (CER) in plasma were determined as previously reported (51). Plasma cholesterol and triglycerides were quantitated by automated enzymatic techniques on a model VPSS analyzer (Abbott Laboratories, North Chicago, IL). HDL cholesterol was quantified in plasma after dextran sulfate precipitation (52). Plasma apoA-I and apoA-II concentrations were determined by immunoturbidimetric assay (Boehringer-Mannheim GmbH, Mannheim, FRG). The plasma LpA-I concentration was measured by the method described by Parra et al. ( 10$)$ and expressed as the apoA-I mass ( $\mathrm{mg}$ ) in LpA-I per volume plasma ( $\mathrm{dl})$. The apoA-I concentration in LpA-I:A-II was obtained by subtracting the LpA-I value from the total plasma apoA-I concentration.

\section{Results}

Lipoprotein and apolipoprotein analysis. The lipid and apolipoprotein concentrations, LCAT activity, and CER of the study subjects are included in Table II. All five patients had very low levels of LCAT activity as determined with the proteoliposome assay. The absence of CER is characteristic of complete LCAT deficiency, whereas the presence of some cholesterol esterification biochemically confirms the diagnosis of partial LCAT deficiency. The triglycerides were substantially elevated in the complete LCAT-deficient patient and variably elevated in the partial LCAT-deficient patients. ApoA-I levels were decreased to $30 \%$ of normal and apoA-II levels to $23 \%$ of normal. Plasma levels of LpA-I were decreased to $51 \%$ of normal and levels of LpA-I:A-II were markedly decreased to $18 \%$ of normal. An average of $62 \%$ of apoA-I was present in LpA-I in the LCAT-deficient patients compared with only $35 \%$ in the control subjects. Therefore, in both complete and partial LCAT deficiency, there is a disproportionate decrease in plasma levels of apoA-II and LpA-I:A-II compared with apoA-I and LpA-I.

ApoA-I and apoA-II kinetics. The apoA-I and apoA-II radiotracer plasma curves in the LCAT-deficient patients compared with representative control subjects studied at the same time with the same radiolabeled apolipoproteins are illustrated in Fig. 1. Both apoA-I and apoA-II were rapidly catabolized compared with controls. In contrast to the control subjects, apoA-II was consistently catabolized substantially faster than apoA-I in the LCAT-deficient patients. This rapid disappearance of the radiolabeled apoA-I and apoA-II from the plasma was not due to differential extravascular redistribution of the radiolabeled apolipoproteins. This is established by the urine to plasma ratios shown in Fig. 2. Because urinary radioactivity represents catabolism of the radiotracer, the higher urine to plasma ratios in the LCAT-deficient patients confirm that 
Table II. LCAT Activity, CER, Lipid, and Apolipoprotein Values in Study Subjects

\begin{tabular}{|c|c|c|c|c|c|c|c|c|c|c|}
\hline Subjects & LCAT activity & CER & TG & TC & HDL & ApoA-I & ApoA-II & LpA-I & LpA-I:A-II & Percent LpA-I \\
\hline & \multicolumn{2}{|c|}{$n m o l / m l-h$} & \multicolumn{7}{|c|}{$m g / d l$} & $\%$ \\
\hline \multicolumn{11}{|l|}{ LCAT deficiency } \\
\hline 1 & 1.5 & $<1$ & 689 & 210 & 4 & 42 & 11 & 19 & 23 & 45 \\
\hline 2 & 7.1 & 49 & 194 & 154 & 4 & 35 & 10 & 24 & 11 & 69 \\
\hline 3 & 14.0 & 25 & 429 & 139 & 7 & 44 & 8 & 29 & 15 & 66 \\
\hline 4 & 18.0 & 16 & 210 & 175 & 10 & 52 & 7 & 30 & 22 & 58 \\
\hline 5 & 0.9 & 51 & 149 & 215 & 8 & 26 & 4 & 18 & 8 & 70 \\
\hline Controls $(n=30)$ & 101.2 & 62 & 72 & 162 & 53 & 136 & 34 & 47 & 89 & 35 \\
\hline SD & 8.4 & 6 & 29 & 28 & 10 & 15 & 6 & 9 & 15 & 4 \\
\hline
\end{tabular}

Abbreviations: TC, total cholesterol; TG, triglycerides.

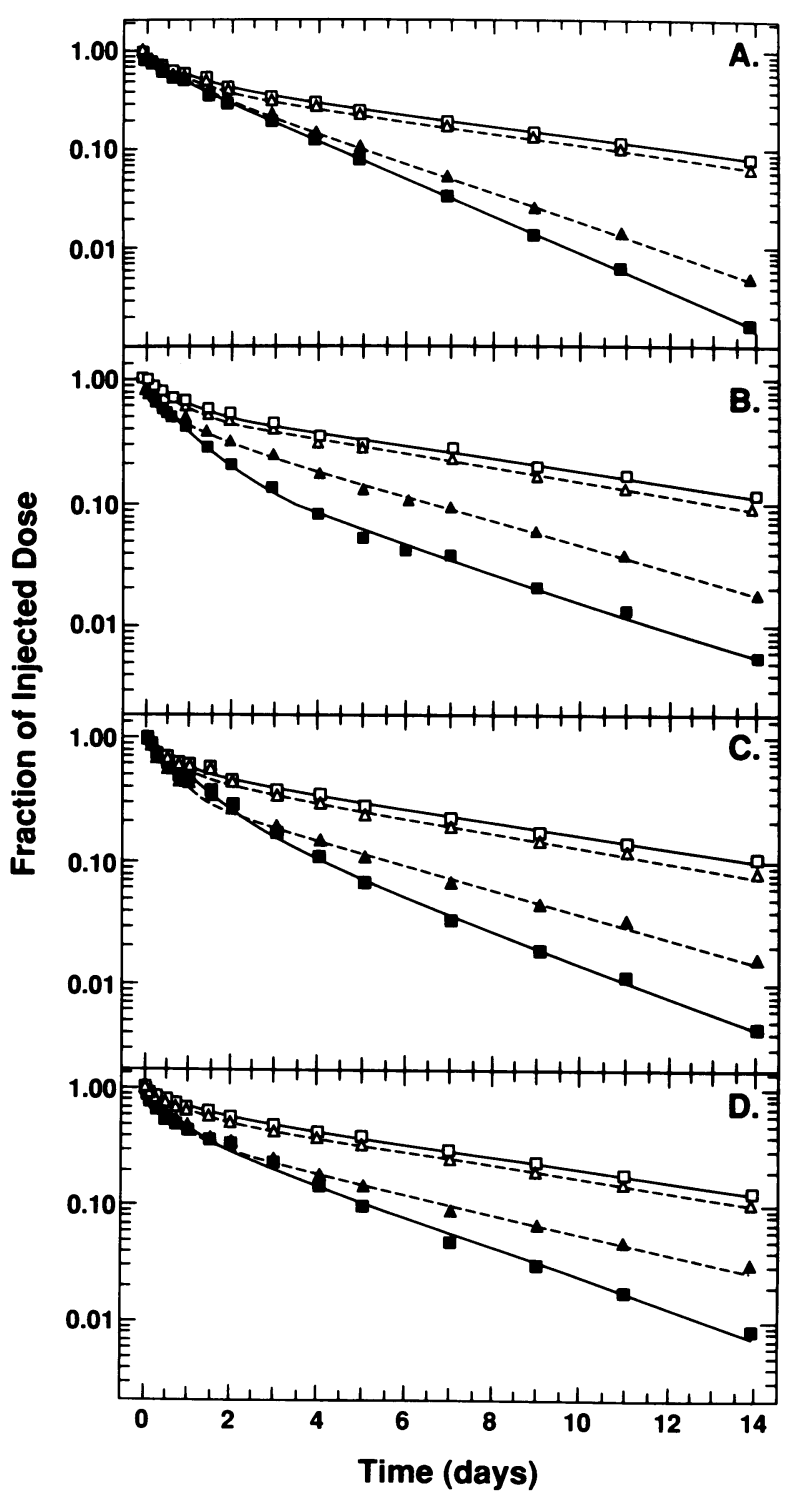

Figure 1. Total plasma radioactivity curves for apoA-I (triangles) and apoA-II (squares) in the classic LCAT-deficient patient $1(A)$ and in partial LCAT-deficient patients $2(B), 3(C)$, and $4(D)$. Each patient is compared with a normal control studied at the same time with the same radiolabeled apolipoproteins. Solid symbols represent patients, open symbols controls.
apoA-I and apoA-II were catabolized much more rapidly in the patients than in controls. Furthermore, in all patients the apoA-II urine to plasma ratios were higher than those of apoAI, consistent with more rapid catabolism of apoA-II.

In the four partial LCAT-deficient patients, endogenous labeling of apoA-I and apoA-II was performed using $\mathrm{D}_{3}$-leucine. The leucine isotopic enrichment curves for apoA-I and apoA-II in these patients are illustrated in Fig. 3. The slope of the isotopic enrichment curve is proportional to the fractional rate of turnover of the apolipoprotein. Endogenous labeling confirmed the rapid turnover of apoA-I and apoA-II in these four patients compared with normal controls. This method also confirmed that apoA-II turnover was faster than that of apoA-I in all four partial LCAT-deficient patients.

The kinetic parameters of apoA-I and apoA-II metabolism are summarized in Table III. ApoA-I was catabolized 2.4 times faster than normal in the complete LCAT-deficient patient and a mean of 2.2 times faster in the partial LCAT-deficient patients. ApoA-II was catabolized 3.0 times faster than normal in the complete LCAT-deficient patient and a mean of 3.1 times faster in the partially deficient patients. Production rates of both apoA-I and apoA-II were relatively normal in all patients, indicating that the decreased plasma levels of apoA-I and apoA-II were due solely to rapid catabolism of these apolipoproteins.

LpA-I and LpA-I:A-II kinetics. The catabolism of apoA-I in LpA-I and LpA-I:A-II in the LCAT-deficient patients and 10 normal subjects is illustrated in Fig. 4. In normal subjects, apoA-I in LpA-I is catabolized faster than that in LpA-I:A-II. In contrast, in the LCAT-deficient patients, apoA-I in LpA-I:A-II was catabolized much faster than that in LpA-I. There was an initial increase in the radiolabeled apoA-I associated with LpA$I$ in these patients, suggesting that there may have been transfer from LpA-I:A-II.

Density subfraction distribution and kinetics. The percent distribution of the radiolabeled apoA-I and apoA-II in lipoprotein subfractions 10 min after injection is provided in Table IV. The patients had a substantial amount of $\mathrm{HDL}_{2}$ apoA-I (39\% of total) and apoA-II (48\% of total), and $\mathrm{HDL}_{3}$ apoA-I (28\%) and apoA-II (42\%). There was significantly more apoA-I in the "lipid deficient" fraction $(d>1.21 \mathrm{~g} / \mathrm{ml})$ in the LCAT-deficient patients $(28 \%)$ compared with controls $(10 \%)$; in contrast, there was relatively little apoA-II in this fraction in patients $(7 \%)$ or controls $(2 \%)$. The kinetic curves of apoA-I in the density subfractions are illustrated in Fig. 5. ApoA-I in 


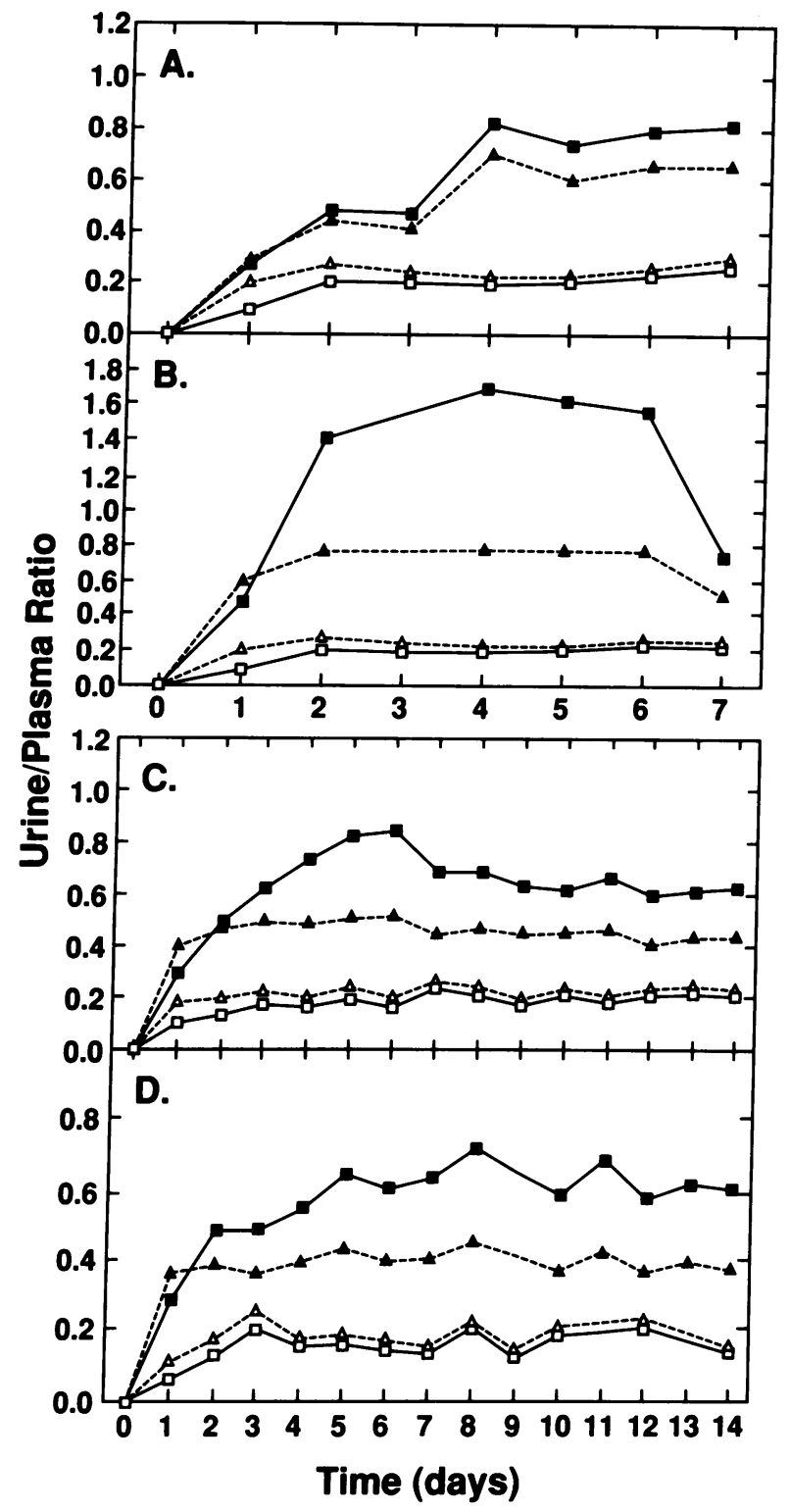

Figure 2. Urine/plasma radioactivity ratios for apoA-I (triangles) and apoA-II ( squares) in the classic LCAT-deficient patient $1(A)$ and in partial LCAT-deficient patients $2(B), 3(C)$, and $4(D)$. Each patient is compared with a normal control studied at the same time with the same radiolabeled apolipoproteins. Solid symbols represent patients, open symbols controls.

$\mathrm{HDL}_{2}$ (Fig. $5 \mathrm{~A}$ ) and $\mathrm{HDL}_{3}$ (Fig. $5 \mathrm{~B}$ ) was catabolized much more rapidly in the LCAT-deficient patients than in control subjects. In contrast, apoA-I in the lipid-deficient fraction was catabolized at a similar rapid rate in both normal subjects and the LCAT-deficient patients (Fig. $5 C$ ).

\section{Discussion}

The physiologic roles of LCAT in HDL metabolism, reverse cholesterol transport, and atherogenesis have not been definitively elucidated. Although rare, patients with genetic defects in LCAT may provide important insights into the function(s) of LCAT in humans. Complete (classic) LCAT deficiency, in which virtually no cholesterol esterification is present in

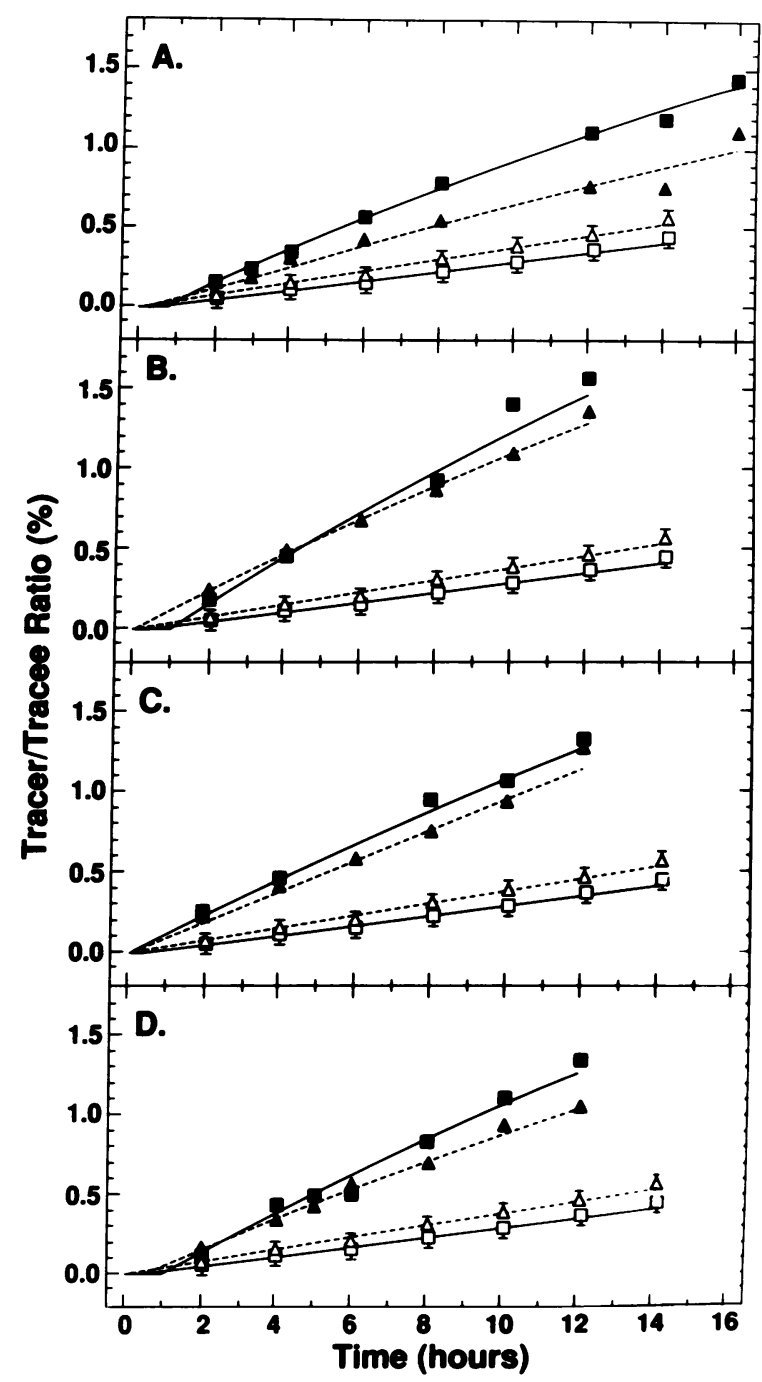

Figure 3. $\mathrm{D}_{3}$-leucine endogenous labeling tracer/tracee curves for apoA-I (triangles) and apoA-II (squares) in the four partial LCAT-deficient patients 2-5 $(A-D)$. Mean apoA-I and apoA-II curves from four control subjects are included in each panel for comparison. Solid symbols represent patients, open symbols controls.

plasma, results in corneal opacities, anemia, proteinuria, and renal insufficiency (23). Patients with partial LCAT deficiency (Fish-eye disease), who have a variable amount of plasma cholesterol esterification, also develop corneal opacities but not anemia or renal disease (23). Both disorders are characterized by very low plasma levels of HDL cholesterol as well as apoA-I and apoA-II.

Plasma HDL particles have been extensively studied in classic LCAT deficiency. Glomset et al. (53) first demonstrated that HDL from LCAT-deficient patients consisted of both high and low molecular weight lipoproteins, an observation that was confirmed by other investigators $(54,55)$. Electron microscopic studies of the HDL particles revealed large disks ranging from 15 to $25 \mathrm{~nm}$ in width that formed rouleaux and small spheres ranging from 4.5 to $6 \mathrm{~nm}$ (56-59). Torsvik et al. (58) reported that the large discs contained both apoA-I and apoAII, whereas the small spheres contained primarily apoA-I. The small spherical particles have a density of $1.16-1.25 \mathrm{~g} / \mathrm{ml}$ and contain 2 mol apoA-I per particle (60). In addition, a subclass 
Table III. Kinetic Parameters of ApoA-I and ApoA-II Metabolism in LCAT-deficient Subjects

\begin{tabular}{|c|c|c|c|c|c|c|c|c|}
\hline \multirow[b]{3}{*}{ Subjects } & \multicolumn{4}{|c|}{ ApoA-I } & \multicolumn{4}{|c|}{ ApoA-II } \\
\hline & \multirow[b]{2}{*}{ Conen. } & \multicolumn{2}{|c|}{ RT } & \multirow[b]{2}{*}{ PR } & \multirow[b]{2}{*}{ Concn. } & \multicolumn{2}{|c|}{ RT } & \multirow[b]{2}{*}{ PR } \\
\hline & & Exog. & Endog. & & & Exog. & Endog. & \\
\hline & $m g / d l$ & & & $m g / k g-d$ & $m g / d l$ & & & $m g / k g-d$ \\
\hline \multicolumn{9}{|l|}{ LCAT deficiency } \\
\hline 1 & 42 & 1.96 & - & 13.0 & 11 & 1.77 & - & 3.24 \\
\hline 2 & 35 & 2.30 & 1.94 & 9.5 & 10 & 1.51 & 1.13 & 3.59 \\
\hline 3 & 44 & 1.93 & 1.85 & 14.0 & 8 & 1.69 & 1.49 & 2.51 \\
\hline 4 & 52 & 2.41 & 2.15 & 13.3 & 7 & 1.98 & 1.92 & 1.88 \\
\hline 5 & 26 & - & 1.78 & 8.8 & 4 & - & 1.35 & 1.54 \\
\hline Mean & 40 & 2.15 & 1.93 & 11.7 & 8 & 1.74 & 1.47 & 2.55 \\
\hline $\mathrm{SD}$ & 10 & 0.24 & 0.16 & 2.4 & 3 & 0.19 & 0.33 & 0.87 \\
\hline Controls $(n=30)$ & 136 & 4.74 & - & 11.9 & 34 & 5.25 & - & 2.74 \\
\hline SD & 15 & 0.65 & - & 2.1 & 6 & 0.61 & - & 0.74 \\
\hline
\end{tabular}

Abbreviations: concn., concentration; endog., endogenous; exog., exogenous.

of the large discoidal particles are rich in apoE (61-63) and probably contain relatively little apoA-I or apoA-II. Norum et al. (64) demonstrated that incubation of LCAT-deficient HDL particles with purified LCAT resulted in the formation of particles intermediate in size between the large and small lipoproteins. Incubation of the small spherical particles alone with LCAT resulted in an increase in particle size (60). Studies of plasma HDL in patients with Fish-eye disease are less extensive but suggest that similar types of lipoprotein particles exist in this disorder. Electron microscopic analysis of HDL from the original patients revealed two major subpopulations: large discoidal particles $17.4 \mathrm{~nm}$ in width and small spherical particles

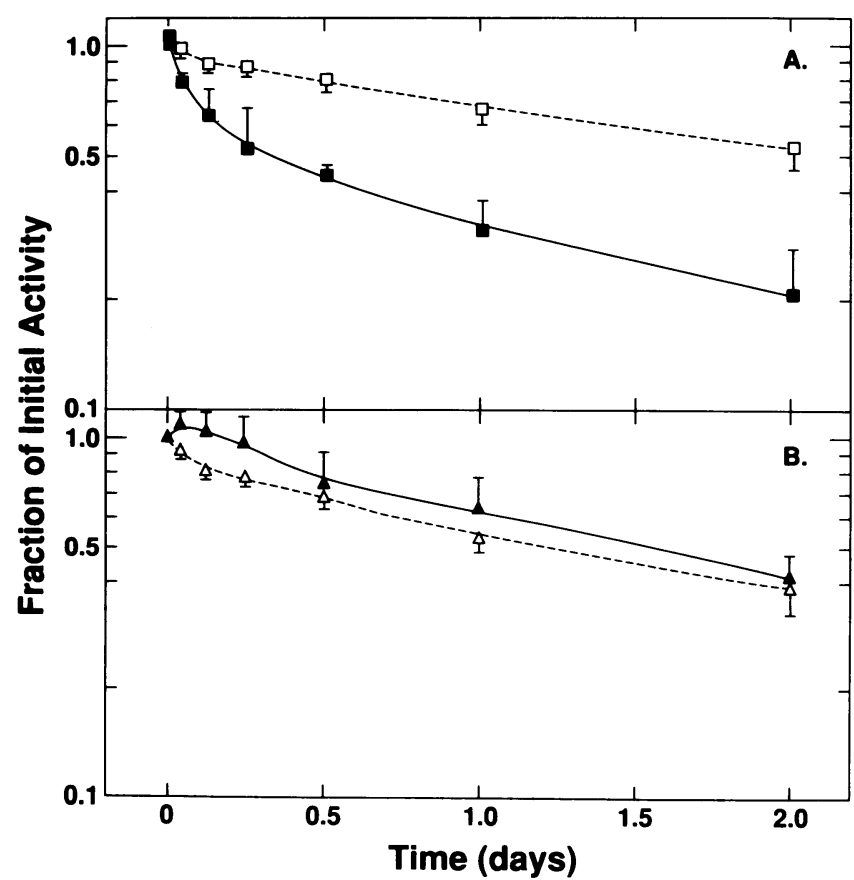

Figure 4. Metabolism of apoA-I in LpA-I:A-II $(A)$ and LpA-I $(B)$. Data points represent the means of 4 LCAT-deficient patients (solid symbols) and 10 controls (open symbols).
$7.6 \mathrm{~nm}$ in diameter (65), a finding confirmed by nondenaturing gradient gel electrophoresis. These combined results indicate that there are two major classes of HDL particles in classic LCAT deficiency and Fish-eye disease: large discoidal particles in the $\mathrm{HDL}_{2}$ density range containing apoA-I and apoA-II, and small spherical particles in the small $\mathrm{HDL}_{3}$ to $d>1.21 \mathrm{~g} / \mathrm{ml}$ range containing apoA-I without apoA-II. The small particles containing only apoA-I resemble small LpA-I particles preparatively isolated from normolipidemic subjects (66).

It has been suggested that the HDL isolated from LCAT-deficient patients may represent nascent HDL particles. Similar particles have been isolated from perfusates of rat $(67,68)$ and monkey (69) livers, from rat mesenteric lymph (70), and from HepG2 cell media $(71,72)$. HepG2 cells were found to secrete large discoidal LpA-I:A-II particles up to $17 \mathrm{~nm}$ in diameter enriched in free cholesterol and small spherical LpA-I particles $<8 \mathrm{~nm}$ in diameter containing much less free cholesterol (72). These findings are consistent with the descriptions of HDL particles present in the plasma of classic LCAT-deficient and Fish-eye disease patients.

The studies reported here establish the mechanism for low levels of apoA-I and apoA-II in classic LCAT deficiency and in Fish-eye disease. ApoA-I and apoA-II are very rapidly catabolized in both complete as well as partial LCAT deficiency, with little difference between these two disorders in their apolipoprotein kinetics. Furthermore, in contrast to normal subjects, apoA-II is catabolized significantly faster than apoA-I in these disorders. The results from radiotracer kinetic studies were supported by the data obtained with endogenous labeling of apoA-I and apoA-II using $\mathrm{D}_{3}$-leucine. In normolipidemic subjects, the catabolism of apoA-II is slower than that of apoA-I (3-6). Although one study reported that apoA-II catabolism was faster than apoA-I in hypertriglyceridemia (73), three other studies were not consistent with this observation (7476). In classic LCAT deficiency and Fish-eye disease, the faster catabolism of apoA-II than of apoA-I is not secondary to hypertriglyceridemia, in that three of the patients we studied had normal plasma triglyceride levels. Therefore, the underlying defect in LCAT itself is the basis for the rapid apoA-II catabolism. 


\begin{tabular}{|c|c|c|c|c|c|c|}
\hline \multirow[b]{2}{*}{ Subject } & \multicolumn{3}{|c|}{ ApoA-I } & \multicolumn{3}{|c|}{ ApoA-II } \\
\hline & $\mathrm{HDL}_{2}$ & $\mathrm{HDL}_{3}$ & $d>1.21^{*}$ & $\mathrm{HDL}_{2}$ & $\mathrm{HDL}_{3}$ & $d>1.21^{*}$ \\
\hline & & & & & & \\
\hline \multicolumn{7}{|l|}{ LCAT deficiency } \\
\hline 1 & 34.5 & 8.0 & 46.2 & 46.3 & 14.3 & 13.2 \\
\hline 2 & 19.2 & 44.8 & 30.5 & 28.8 & 55.9 & 11.1 \\
\hline 3 & 51.8 & 27.7 & 17.7 & 54.6 & 40.5 & 2.6 \\
\hline 4 & 50.4 & 31.2 & 16.3 & 62.2 & 32.4 & 1.8 \\
\hline Mean & 39.0 & 27.9 & 27.7 & 48.0 & 41.9 & 7.2 \\
\hline SD & 15.3 & 15.2 & 13.9 & 14.3 & 16.1 & 5.8 \\
\hline Controls $(n=10)$ & 44.8 & 43.3 & 9.5 & 42.7 & 53.4 & 2.4 \\
\hline $\mathrm{SD}$ & 9.3 & 10.6 & 3.0 & 16.4 & 18.2 & 0.6 \\
\hline
\end{tabular}

* The plasma fraction of density $>1.21 \mathrm{~g} / \mathrm{ml}$.

In classic LCAT deficiency, the fraction of plasma and HDL unesterified to total cholesterol is much higher than normal, and the excess of HDL unesterified cholesterol has been postulated to play a causal role in the abnormal HDL metabolism. In some cases of Fish-eye disease, the LCAT activity associated with HDL is reduced but the LCAT activity associated with apoB-containing lipoproteins is preserved $(23,77)$. The fraction of plasma cholesterol which is unesterified is not nearly as elevated as it is in complete $\operatorname{LCAT}$ deficiency $(37,38$, 78 ). Even within HDL, the fraction of unesterified cholesterol is not as high, $(37,78,79)$, presumably due to transfer of cholesteryl ester into HDL from apoB-containing particles. Therefore, if the rapid catabolism of apoA-I and apoA-II in complete LCAT deficiency were due simply to the high fraction of unesterified cholesterol in HDL, the kinetics of apoA-I and apoA-II

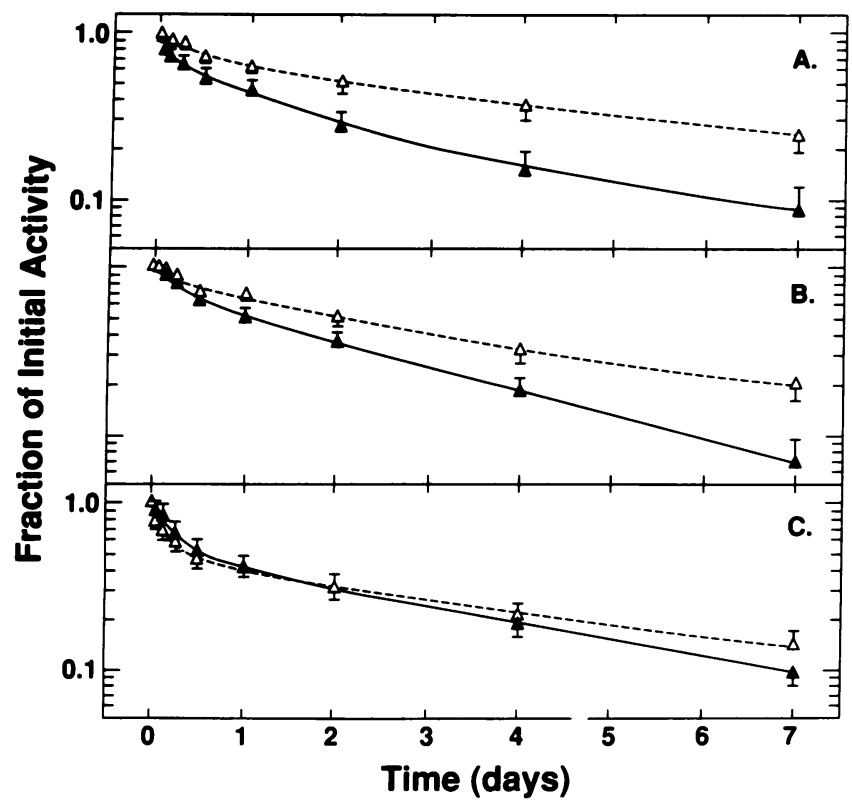

Figure 5. Metabolism of apoA-I in $\mathrm{HDL}_{2}(A), \mathrm{HDL}_{3}(B)$, and the $d$ $>1.21 \mathrm{~g} / \mathrm{ml}$ fraction $(C)$. Data points represent the means of 4 LCAT-deficient patients (solid symbols) and 10 controls (open symbols). should not be affected to the same extent in the more subtle syndrome of partial LCAT deficiency. However, we found that the catabolic rates of apoA-I and apoA-II in the partially LCAT-deficient patients were as rapid as those in complete LCAT deficiency.

The production rates of both apoA-I and apoA-II in the LCAT-deficient patients were within the normal range, indicating that hypercatabolism is the sole cause of the low apoA-I and apoA-II levels in these disorders. These findings provide insight into the role of LCAT in the regulation of HDL metabolism and indicate a specific effect of LCAT deficiency on the metabolism of apoA-II-containing lipoproteins.

The kinetics of apoA-I in two siblings with LCAT deficiency were reported recently by Gylling et al. (80). These siblings had apoA-I levels $28 \%$ and $45 \%$ of normal and apoA-II levels $20 \%$ and $32 \%$ of normal. The apoA-I residence times were 0.99 and $3.48 \mathrm{~d}$, respectively, with apoA-I production rates which were higher than normal in one case and lower in the other case. The reason for the marked difference in apoA-I kinetics between the two siblings was not clear. Our results indicate that the apoA-I catabolic rate in LCAT deficiency is approximately two to three times that in normal subjects, in between those of the two patients reported by Gylling et al. (80).

In order to gain further insight into the accelerated catabolism of apoA-I and apoA-II, we analyzed the catabolism of apoA-I on LpA-I and LpA-I:A-II classic LCAT deficiency and Fish-eye disease. We previously reported that in normal subjects apoA-I on the LpA-I particle is catabolized at a faster rate than apoA-I on the LpA-I:A-II particle (11). We investigated the lipoprotein particle metabolism in patients with classic LCAT deficiency and Fish-eye disease by isolating LpA-I and LpA-I:A-II from plasma samples at different times after injection. In contrast with normal subjects, the apoA-I on LpA-I:AII was catabolized at a much faster rate than apoA-I on LpA-I in the LCAT-deficient patients. This finding, combined with the overall more rapid catabolism of apoA-II than apoA-I, suggests that in LCAT-deficient states LpA-I:A-II is catabolized faster than LpA-I and is consistent with the very low levels of LpA-I:A-II we found in the LCAT-deficient patients compared with LpA-I. These results provide additional support for the concept that LpA-I and LpA-I:A-II are metabolically distinct particles which have divergent in vivo metabolism. 
Other investigators have found differences in LCAT activity between LpA-I and LpA-I:A-II. A greater fraction of plasma LCAT was associated with LpA-I rather than LpA-I:A-II despite the fact that the former is in lower concentration in normal subjects (81). LpA-I:A-II, but not LpA-I, required apoBcontaining lipoproteins in order to be transformed by the action of LCAT (82). Finally, LDL-derived free cholesterol was first transferred to large $\mathrm{HDL}_{2}$ particles (83); in contrast, small LpA-I particles were the primary acceptors of free cholesterol from fibroblasts ( 84 ). These data suggest that LpA-I:A-II may be the preferred particle for the LCAT-mediated esterification of free cholesterol derived from apoB-containing particles and support the concept that LCAT deficiency could have different effects on the metabolism of LpA-I and LpA-I:A-II.

We also analyzed the distribution and kinetics of apoA-I and apoA-II in the HDL density subclasses in the LCAT-deficient patients. A substantial quantity of radiolabeled apoA-I and apoA-II were isolated in the $\mathrm{HDL}_{2}$ and $\mathrm{HDL}_{3}$ density ranges, whereas a large amount of apoA-I, but not apoA-II, was present in the lipid-deficient $(d>1.21 \mathrm{~g} / \mathrm{ml})$ fraction. In normal subjects, the catabolism of apoA-I in $\mathrm{HDL}_{2}$ and $\mathrm{HDL}_{3}$ was slower than in the $d>1.21 \mathrm{~g} / \mathrm{ml}$ fraction. In the LCAT-deficient patients, the catabolism of apoA-I in $\mathrm{HDL}_{2}$ and $\mathrm{HDL}_{3}$ was much faster than in normal $\mathrm{HDL}_{2}$. In contrast, the catabolism of the apoA-I in the $d>1.21$ fraction was similar to that seen in normal subjects.

Based on this data, we propose the following working model for HDL metabolism in complete and partial LCAT deficiency. The large discoidal particles found in these disorders contain both apoA-I and apoA-II and represent the majority of the LpA-I:A-II particles in the plasma. In the absence of active cholesterol esterification, these particles are very rapidly catabolized, possibly due either to their discoidal structure, apoE content, or altered apoA-I or apoA-II conformation. These large particles are unlikely to participate actively in cholesterol removal from peripheral cells. In contrast, small spherical particles containing only apoA-I represent the majority of the LpA-I particles in the plasma of LCAT-deficient patients. These particles are similar in size to those isolated from normal plasma (66) and are catabolized at a rate similar to that of small LpA-I particles in normal subjects. Given their size, lipid, and apolipoprotein composition, these small particles may be important in promoting cholesterol efflux from cells and maintaining effective reverse cholesterol transport in LCAT-deficient patients.

These results are of interest in light of the fact that neither classic LCAT deficiency nor Fish-eye disease is associated with an increased risk of premature atherosclerosis, despite the very low plasma levels of HDL cholesterol and apoA-I (23). It has been proposed that LpA-I may be a specific antiatherogenic particle within HDL; LpA-I:A-II may even be antagonistic to the effects of LpA-I (16-18). In this context, it is interesting that classic LCAT-deficient and Fish-eye syndrome patients have extremely low levels of LpA-I:A-II and only moderately decreased levels of LpA-I, due to the selective effect of LCAT deficiency on the catabolism of LpA-I:A-II particles. It is possible that because the LpA-I system is relatively preserved and the ratio of LpA-I to LpA-I:A-II increased, the risk of premature atherosclerosis is not substantially increased in these disorders.

In summary, our results establish that markedly accelerated catabolism of apoA-II and LpA-I:A-II occurs not only in the severe clinical syndrome of complete (classic) LCAT deficiency, but also in the more subtle condition of partial LCAT deficiency (Fish-eye syndrome). These results indicate that LCAT deficiency has a selective effect on the metabolism of lipoproteins containing apoA-II and suggest that conditions of low HDL due to increased catabolism of LpA-I:A-II may not be associated with a substantially increased risk of premature coronary heart disease.

\section{Acknowledgments}

We are indebted to Marie Kindt, Glenda Talley, and Rosemary Ronan for excellent technical assistance, George Grimes of the Pharmaceutical Development Service for evaluation of the $\mathrm{D}_{3}$-leucine, Betty Kuzmik and the nursing staff of the 8 East inpatient ward of the NIH Clinical Center for care of the study subjects, Patti Riggs and the Metabolic Kitchen for invaluable dietary assistance, Loan Kusterbeck for secretarial assistance, and the study subjects for participating.

\section{References}

1. Gordon, D. J., and B. M. Rifkind. 1989. High-density lipoprotein-the clinical implications of recent studies. N. Engl. J. Med. 321:1311-1316.

2. Miller, N. E. 1987. Associations of high-density lipoprotein subclasses and apolipoproteins with ischemic heart disease and coronary atherosclerosis. $\mathrm{Am}$. Heart J. 113:589-597.

3. Schaefer, E. J., L. A. Zech, L. L. Jenkins, T. J. Bronzert, E. A. Rubalcaba, R. T. Lindgren, R. L. Aamodt, and H. B. Brewer, Jr. 1982. Human apolipoprotein A-I and A-II metabolism. J. Lipid Res. 23:850-862.

4. Zech, L. A., E. J. Schaefer, T. J. Bronzert, R. L. Aamodt, and H. B. Brewer, Jr. 1983. Metabolism of human apolipoproteins A-I and A-II: compartmental models. J. Lipid Res. 24:60-71.

5. Brinton, E. A., S. Eisenberg, and J. L. Breslow. 1989. Elevated high density lipoprotein cholesterol levels correlate with decreased apolipoprotein A-I and A-II fractional catabolic rate in women. J. Clin. Invest. 84:262-269.

6. Brinton, E. A., S. Eisenberg, and J. L. Breslow. 1990. A low-fat diet decreases high density lipoprotein (HDL) cholesterol levels by decreasing HDL apolipoprotein transport rates. J. Clin. Invest. 85:144-151.

7. Alaupovic, P., D. M. Lee, and W. J. McConathy. 1972. Studies on the composition and structure of plasma lipoproteins: distribution of lipoprotein families in major density classes of normal human plasma lipoproteins. Biochim. Biophys. Acta. 260:689-707.

8. Cheung, M. C., and J. J. Albers. 1984. Characterization of lipoprotein particles isolated by immunoaffinity chromatography: particles containing A-I and A-II and particles containing A-I but no A-II. J. Biol. Chem. 259:1220112209.

9. Koren, E., P. Puchois, P. Alaupovic, J. Fesmire, A. Kandoussi, and J. C. Fruchart. 1987. Quantification of two different types of apolipoprotein A-I containing lipoprotein particles in plasma by enzyme-linked differential-antibody immunosorbent assay. Clin. Chem. 33:38-43.

10. Parra, H. J., H. Mezdour, N. Ghalim, J. M. Bard, and J. C. Fruchar. 1990. Differential electroimmunoassay of human LpA-I lipoprotein particles on readyto-use plates. Clin. Chem. 36:1431-1435.

11. Rader, D. J., G. Castro, L. A. Zech, J. C. Fruchart, and H. B. Brewer, Jr. 1991. In vivo metabolism of apolipoprotein A-I on high density lipoprotein particles LpA-I and LpA-I, A-II. J. Lipid Res. 32:1849-1859.

12. Puchois, P., A. Kandoussi, P. Fievet, J. L. Fourrier, M. Bertrand, E. Koren, and J. C. Fruchart. 1987. Apolipoprotein A-I containing lipoproteins in coronary artery disease. Atherosclerosis. 68:35-40.

13. Stampfer, M. J., F. M. Sacks, S. Salvini, W. C. Willett, and C. H. Hennekens. 1991. A prospective study of cholesterol, apolipoproteins, and the risk of myocardial infarction. N. Engl. J. Med. 325:373-381.

14. Parra, H. J., D. Arveiler, A. E. Evans, J. P. Cambou, P. Amouyel, A Bingham, D. McMaster, P. Schaffer, P. Douste-Blazy, G. Luc, et al. 1992. A case-control study of lipoprotein particles in two populations at contrasting risk for coronary heart disease: the ECTIM study. Arterioscler. Thromb. 12:701-707.

15. Barbaras, R., P. Puchois, J. C. Fruchart, and G. Ailhaud. 1987. Cholesterol efflux from cultured adipose cells is mediated by LpAI particles but not by LpAI:AII particles. Biochem. Biophys. Res. Commun. 142:63-69.

16. Schultz, J. R., J. G. Verstuyft, E. L. Gong, A. V. Nichols, and E. M. Rubin. 1993. Protein composition determines the anti-atherogenic properties of HDL in transgenic mice. Nature (Lond.). 365:762-764.

17. Mehrabian, M., J. H. Qiao, R. Hyman, D. Ruddle, C. Laughton, and A. J. Lusis. 1993. Influence of the apoA-II gene locus on HDL levels and fatty streak development in mice. Arterioscler. Thromb. 13:1-10. 
18. Warden, C. H., C. C. Hedrick, J.-H. Qiao, L. W. Castllani, and A. J. Lusis. 1993. Atherosclerosis in transgenic mice overexpressing apolipoprotein A-II. Science (Wash. DC). 261:469-472.

19. Glomset, J. A. 1968. The plasma lecithins:cholesterol acyltransferase reaction. J. Lipid Res. 9:155-167.

20. Glomset, J. A., E. T. Janssen, R. Kennedy, and J. Dobbins. 1966. Role of plasma lecithin:cholesterol acyltransferase in the metabolism of high density lipoproteins. J. Lipid Res. 7:638-48.

21. Dobiasova, M. 1983. Lecithin:cholesterol acyltransferase and the regulation of endogenous cholesterol transport. Adv. Lipid Res. 20:107-194.

22. Jonas, A. 1991. Lecithin-cholesterol acyltransferase in the metabolism of high-density lipoproteins. Biochim. Biophys. Acta. 1084:205-220.

23. Norum, K. R., E. Gjone, and J. A. Glomset. 1989. Familial lecithin: cholesterol acyltransferase deficiency including fish eye disease. In The Metabolic Basis of Inherited Disease. C. R. Scriver, A. L. Beaudet, W. S. Sly, and D. Valle, editors. McGraw-Hill, Inc., New York. 1181-1194.

24. Taramelli, R., M. Pontoglio, G. Candiani, S. Ottolenghi, H. Dieplinger, A. Catapano, J. Albers, C. Vergani, and J. McLean. 1990. Lecithin cholesterol acyl transferase deficiency: molecular analysis of a mutated allele. Hum. Genet. 85:195-199.

25. Bujo, H., J. Kusunoki, M. Ogasawara, T. Yamamoto, Y. Ohta, T. Shimada, Y. Saito, and S. Yoshida. 1991. Molecular defect in familial lecithin:cholesterol acyltransferase (LCAT) deficiency: a single nucleotide insertion in LCAT gene causes a complete deficient type of the disease. Biochem. Biophys. Res. Commun. 181:933-940.

26. Gotoda, T., N. Yamada, T. Murase, M. Sakuma, N. Murayama, H. Shimano, K. Kozaki, J. J. Albers, Y. Yazaki, and Y. Akanuma. 1991. Differentia phenotypic expression by three mutant alleles in familial lecithin:cholesterol acyltransferase deficiency. Lancet. 338:778-781.

27. Skretting, G., J. P. Blomhoff, J. Solheim, and H. Prydz. 1992. The genetic defect of the original Norwegian lecithin:cholesterol acyltransferase deficiency families. Fed. Eur. Biochem. Soc. 309:307-310.

28. Funke, H., A. von Eckardstein, P. H. Pritchard, A. E. Hornby, H. Wiebusch, C. Motti, M. R. Hayden, C. Dachet, B. Jacotot, U. Gerdes, et al. 1993. Genetic and phenotypic heterogeneity in familial lecithin: cholesterol acyltransferase (LCAT) deficiency. J. Clin. Invest. 91:677-683.

29. Klein, H.-G., P. Lohse, N. Duverger, J. J. Albers, D. J. Rader, L. A. Zech S. Santamarina-Fojo, and H. B. Brewer, Jr. 1993. Two different allelic mutations in the lecithin:cholesterol acyltransferase (LCAT) gene resulting in classic LCAT deficiency: LCAT (tyr83 $\rightarrow$ stop) and LCAT (tyr156 $\rightarrow$ asn). J. Lipid Res. 34:49-58.

30. Carlson, L. A. and L. Holmquist. 1985. Evidence for deficiency of high density lipoprotein lecithin: cholesterol acyltransferase activity (alpha-LCAT) in fish eye disease. Acta Med. Scand. 218:189-196.

31. Carlson, L. A. and L. Holmquist. 1985. Evidence for the presence in human plasma of lecithin: cholesterol acyltransferase activity (beta-LCAT) specifically esterifying free cholesterol of combined pre-beta- and beta-lipoproteins: studies of fish eye disease patients and control subjects. Acta Med. Scand. 218:197-205.

32. Funke, H., A. von Eckardstein, P. H. Pritchard, J. J. Albers, J. J. P. Kastelein, C. Droste, and G. Assmann. 1991. A molecular defect causing fish eye disease: an amino acid exchange in lecithin-cholesterol acyltransferase (LCAT) leads to the selective loss of $\alpha$-LCAT activity. Proc. Natl. Acad. Sci. USA. 88:4855-4859.

33. Skretting, G. and H. Prydz. 1992. An amino acid exchange in exon I of the human lecithin: cholesterol acyltransferase (LCAT) gene is associated with fish eye disease. Biochem. Biophys. Res. Commun. 182:583-587.

34. Klein, H.-G., P. Lohse, P. H. Pritchard, D. Bojanovski, H. Schmidt, and H. B. Brewer, Jr. 1992. Two different allelic mutations in the lecithin-cholesterol acyltransferase gene associated with the fish eye syndrome: lecithin-cholesterol acyltransferase ( $\left.\mathrm{Thr}_{123} \rightarrow \mathrm{Ile}\right)$ and lecithin-cholesterol acyltransferase $\left(\mathrm{Thr}_{347} \rightarrow\right.$ Met). J. Clin. Invest. 89:499-506.

35. Klein, H.-G., S. Santamarina-Fojo, N. Duverger, M. Clerc, M.-F. Dumon, J. J. Albers, S. Marcovina, and H. B. Brewer, Jr. 1993. Fish eye syndrome: a molecular defect in the lecithin-cholesterol acyltransferase (LCAT) gene associated with normal alpha-LCAT specific activity. J. Clin. Invest. 92:479-485.

36. Lager, D. J., B. F. Rosenberg, H. Shapiro, and J. Bernstein. 1991. Lecithin cholesterol acyltransferase deficiency: ultrastructural examination of sequentia renal biopsies. Mod. Pathol. 4:331-335.

37. Frohlich, J., G. Hoag, R. McLeod, M. Hayden, D. V. Godin, L. D. Wadsworth, J. D. Critchley, and P. H. Pritchard. 1987. Hypoalphalipoproteinemia resembling fish eye disease. Acta Med. Scand. 221:291-28.

38. Clerc, M., M. F. Dumon, D. Sess, M. Freneix-Clerc, M. Mackness, and C. Conri. 1991. A "fish-eye disease" familial condition with massive corneal opacities and hypoalphalipoproteinaemia: clinical, biochemical and genetic features. Eur. J. Clin. Invest. 21:616-624.

39. Lipton, M. J., and W. W. Holt. 1991. Computed tomography for patient management in coronary artery disease. Circulation. 84:I-72-1-80.

40. Brewer, H. B., Jr., T. Fairwell, A. LaRue, R. Ronan, A. Houser, and T. J. Bronzert. 1978. The amino acid sequence of human ApoA-I, an apolipoprotein isolated from high density lipoproteins. Biochem. Biophys. Res. Commun. 80:623-630.

41. Brewer, H. B., Jr., S. E. Lux, R. Ronan, and K. M. John. 1972. Amino acid sequence of human apoLp-Gln-II (apoA-II), an apolipoprotein isolated from the high-density lipoprotein complex. Proc. Natl. Acad. Sci. USA. 69:1304-1308.

42. Berman, M., and M. Weiss. 1978. SAAM Manual. National Institutes of Health, Bethesda, MD. DHEW Publication No. (NIH) 78:180.

43. Wolfe, R. R. 1984. Gas chromatography-mass spectrometry methods. In Tracers in Metabolic Research. Radioisotope and Stable Isotope/Mass Spectrometry Methods. R. R. Wolfe, editor. Alan R. Liss, Inc., New York. 261-271.

44. Schaefer, J. R., D. J. Rader, K. Ikewaki, T. Fairwell, L. A. Zech, M. R. Kindt, J. Davignon, R. E. Gregg, and H. B. Brewer, Jr. 1992. In vivo metabolism of apolipoprotein A-I in a patient with homozygous familial hypercholesterolemia. Arterioscler. Thromb. 12:843-848.

45. Cobelli, C., G. Toffolo, and D. M. Foster. 1992. Tracer-to-tracee ratio for analysis of stable isotope tracer data: link with radioactive kinetic formalism. Am. J. Physiol. 262:E968-E975.

46. Cryer, D. R., T. Matsushima, J. B. Marsh, M. Yudkoff, P. M. Coates, and J. A. Cortner. 1986. Direct measurement of apolipoprotein B synthesis in human very low density lipoprotein using stable isotopes and mass spectrometry. J. Lipid Res. 27:508-516.

47. Cohn, J. S., D. A. Wagner, S. D. Cohn, J. S. Millar, and E. J. Schaefer. 1990. Measurement of very low density and low density lipoprotein apolipoprotein (Apo) B-100 and high density lipoprotein Apo A-I production in human subjects using deuterated leucine: effect of fasting and feeding. J. Clin. Invest. 85:804-811.

48. Ikewaki, K., D. J. Rader, J. R. Schaefer, T. Fairwell, L. A. Zech, and H. B. Brewer, Jr. 1993. Evaluation of apoA-I kinetics in humans using simultaneous endogenous stable isotope and exogenous radiotracer methods. J. Lipid Res. In press.

49. Emmerich, J., B. Verges, I. Tauveron, D. J. Rader, S. Santamarina-Fojo, J. R. Schaefer, M. Ayrault-Jarrier, P. Thieblot, and H. B. Brewer, Jr. 1993. Familial HDL deficiency due to marked hypercatabolism of normal apoA-I. Arter ioscler. Thromb. 13:1299-1306.

50. Havel, R. J., H. A. Eder, and J. H. Bragdon. 1955. The distribution and chemical composition of ultracentrifugally separated lipoproteins in human serum. J. Clin. Invest. 34:1345-1353.

51. Dobiasova, M., J. Stribrna, D. L. Sparks, P. H. Pritchard, and J. J. Frohlich. 1991. Cholesterol esterification rates in very low density lipoprotein- and low density lipoprotein-depleted plasma: relation to high density lipoprotein subspecies, sex, hyperlipidemia, and coronary artery disease. Arteriosclerosis. 11:64-70.

52. Warnick, G. R., M. C. Cheung, and J. J. Albers. 1979. Comparison of current methods for high-density lipoprotein cholesterol quantitation. Clin. Chem. 25:596-604.

53. Glomset, J. A., K. R. Norum, and W. King. 1970. Plasma lipoproteins in familial lecithin:cholesterol acyltransferase deficiency: lipid composition and reactivity in vitro. J. Clin. Invest. 49:1827-1837.

54. Norum, K. R., J. A. Glomset, A. V. Nichols, and T. Forte. 1971. Plasma lipoproteins in familial lecithin:cholesterol acyltransferase deficiency: physica and chemical studies of low and high density lipoproteins. J. Clin. Invest. 50:1131-40.

55. Utermann, G., W. Schoenborn, K. H. Langer, and P. Dieker. 1972. Lipoproteins in LCAT-deficiency. Humangenetik. 16:295-306.

56. Forte, T., K. R. Norum, J. A. Glomset, and A. V. Nichols. 1971. Plasma lipoproteins in familial lecithin:cholesterol acyltransferase deficiency: structure of low and high density lipoproteins as revealed by electron microscopy. J. Clin. Invest. 50:1141-1148.

57. Torsvik, H., M. H. Solaas, and E. Gjone. 1970. Serum lipoproteins in plasma lecithin:cholesterol acyltransferase deficiency, studied by electron microscopy. Clin. Genet. 1:139-150.

58. Torsvik, H. 1972. Studies on the protein moiety of serum high density lipoprotein from patients with familial lecithin:cholesterol acyltransferase deficiency. Clin. Genet. 3:188-200.

59. Soutar, A. K., B. L. Knight, and N. B. Myant. 1982. The characterization of lipoproteins in the high density fraction obtained from patients with familial lecithin:cholesterol acyltransferase deficiency and their interaction with cultured human fibroblasts. J. Lipid Res. 23:380-390.

60. Chen, C., K. Applegate, W. C. King, J. A. Glomset, K. R. Norum, and E. Gjone. 1984. A study of the small spherical high density lipoproteins of patients afflicted with familial lecithin:cholesterol acyltransferase deficiency. J. Lipid Res. 25:269-82.

61. Utermann, G., H. J. Menzel, K. H. Langer, and P. Dieker. 1975. Lipoproteins in lecithin-cholesterol-acyltransferase (LCAT)-deficiency. II. Further studies on the abnormal high-density-lipoproteins. Humangenetik. 27:185-7.

62. Mitchell, C. D., W. C. King, K. R. Applegate, T. Forte, J. A. Glomset, K. R. Norum, and E. Gjone. 1980. Characterization of apolipoprotein E-rich high density lipoproteins in familial lecithin:cholesterol acyltransferase deficiency. J. Lipid Res. 21:625-634.

63. Marcel, Y. L., C. Vezina, D. Emond, and G. Suzue. 1980. Heterogeneity of human high density lipoprotein: presence of lipoproteins with and without 
apoE and their roles as substrates for lecithin:cholesterol acyltransferase reaction. Proc. Natl. Acad. Sci. USA. 77:2969-2973.

64. Norum, K. R., J. A. Glomset, A. V. Nichols, T. Forte, J. J. Albers, W. C. King, C. D. Mitchell, K. R. Applegate, E. L. Gong, V. Cabana, et al. 1975. Plasma lipoproteins in familial lecithin:cholesterol acyltransferase deficiency: effects of incubation with lecithin:cholesterol acyltransferase in vitro. Scand. J. Clin. Lab. Invest. 35:31-55.

65. Forte, T. M., and L. A. Carlson. 1984. Electron microscopic structure of serum lipoproteins from patients with fish eye disease. Arteriosclerosis. 4:130-7.

66. Duverger, N., D. J. Rader, P. Duchateau, J. C. Fruchart, G. Castro, and

H. B. Brewer, Jr. 1993. Biochemical characterization of the three major subclasses of lipoprotein A-I (LpA-I) preparatively isolated from human plasma. Biochemistry. In press.

67. Hamilton, R. L., M. C. Williams, C. J. Fielding, and R. J. Havel. 1976. Discoidal bilayer structure of nascent high density lipoproteins from perfused rat liver. J. Clin. Invest. 58:667-80.

68. Winkler, K. E., and J. B. Marsh. 1989. Characterization of nascent high density lipoprotein subfractions from perfusates of rat liver. J. Lipid Res. 30:979987.

69. Babiak, J., H. Tamachi, F. L. Johnson, J. S. Parks, and L. L. Rudel. 1986. Lecithin:cholesterol acyltransferase-induced modifications of liver perfusate discoidal high density lipoproteins from African green monkeys. J. Lipid Res. 27:1304-117.

70. Green, P. H., A. R. Tall, and R. M. Glickman. 1978. Rat intestine secretes discoid high density lipoprotein. J. Clin. Invest. 61:528-534.

71. McCall, M. R., T. M. Forte, and V. G. Shore. 1988. Heterogeneity of nascent high density lipoproteins secreted by the hepatoma-derived cell line, Hep G2. J. Lipid Res. 29:1127-1137.

72. Cheung, M. C., K. D. Lum, C. G. Brouillette, and C. L. Bisgaier. 1989. Characterization of apoA-I-containing lipoprotein subpopulations secreted by HepG2 cells. J. Lipid Res. 30:1429-1436.

73. Rao, S. N., P. J. Magill, N. E. Miller, and B. Lewis. 1980. Plasma high-density lipoprotein metabolism in subjects with primary hypertriglyceridaemia: altered metabolism of apoproteins AI and AII. Clin. Sci. 59:359-67.

74. Fidge, N., P. Nestel, T. Ishikawa, M. Reardon, and T. Billington. 1980. Turnover of apoproteins A-I and A-II of high density lipoprotein and the relation- ship to other lipoproteins in normal and hyperlipidemic individuals. Metab. Clin. Exp. 29:643-653.

75. Saku, K., P. S. Gartside, B. A. Hynd, S. G. Mendoza, and M. L. Kashyap. 1985. Apolipoprotein AI and AII metabolism in patients with primary high-density lipoprotein deficiency associated with familial hypertriglyceridemia. Metab. Clin. Exp. 34:754-764

76. Brinton, E. A., S. Eisenberg, and J. L. Breslow. 1991. Increased apo A-I and apo A-II fractional catabolic rate in patients with low high density lipoprotein-cholesterol levels with or without hypertriglyceridemia. J. Clin. Invest. 87:536-544.

77. Karmin, O., J. S. Hill, X. Wang, and P. H. Pritchard. 1993. Recombinant lecithin:cholesterol acyltransferase containing a Thr $123 \rightarrow$ Ile mutation esterifies cholesterol in low density lipoprotein but not in high density lipoprotein. J. Lipid Res. 34:81-88.

78. Carlson, L. A. 1982. Fish eye disease: a new familial condition with massive corneal opacities and dyslipoproteinaemia. Eur. J. Clin. Invest. 12:41-53.

79. Carlson, L. A., and L. Holmquist. 1983. Studies on high density lipoproteins in fish eye disease. Acta Med. Scand. 213:177-182.

80. Gylling, H., and T. A. Miettinen. 1992. Non-cholesterol sterols, absorption and synthesis of cholesterol and apolipoprotein A-I kinetics in a Finnish lecithin-cholesterol acyltransferase deficient family. Atherosclerosis. 95:25-33.

81. Cheung, M. C., A. C. Wolf, K. D. Lum, J. H. Tollefson, and J. J. Albers. 1986. Distribution and localization of lecithin:cholesterol acyltransferase and cholesteryl ester transfer activity in A-I-containing lipoproteins. J. Lipid Res. 27:1135-1144.

82. Cheung, M. C., and A. C. Wolf. 1989. In vitro transformation of apoA-Icontaining lipoprotein subpopulations: role of lecithin:cholesterol acyltransferase and apoB-containing lipoproteins. J. Lipid Res. 30:499-509.

83. Fielding, P. E., T. Miida, and C. J. Fielding. 1991. Metabolism of low-density lipoprotein free cholesterol by human plasma lecithin-cholesterol acyltransferase. Biochemistry. 30:8551-8557.

84. Francone, O. L., A. Gurakar, and C. Fielding. 1989. Distribution and functions of lecithin:cholesterol acyltransferase and cholesteryl ester transfer protein in plasma lipoproteins: evidence for a functional unit containing these activities together with apolipoproteins A-I and D that catalyzes the esterification and transfer of cell-derived cholesterol. J. Biol. Chem. 264:7066-7072. 